\title{
Kosmische Musik and Its Techno-Social Context
}

\author{
Alexander C. Harden \\ The University of Surrey \\ a.harden@surrey.ac.uk
}

\begin{abstract}
The electrification of music making in West Germany during the 1970s led to what is now often recognized as one of the most important developments in popular electronic music. In this article, the emergence of kosmische musik ("cosmic music"), a style of electronic music developed during the early 1970s, is contextualized within the social climate of West Germany and post-war attraction to emerging electronic music technologies. Beginning from accounts of the period, which associate kosmische musik with themes of space and otherworldliness, matters of production are positioned as a form of aesthetic demarcation that was encouraged by the technological and social context of West Germany. The approaches to acoustical space, sonic design, and performative agency are then explored in an analysis of Tangerine Dream's "Phaedra".
\end{abstract}

KEYWORDS: kosmische musik, krautrock, production aesthetics, Germany

\section{Introduction}

During the early 1970s, West Germany was home to a remarkable development in music making, fostered by the pursuit of new creative practices amid uncertain social surroundings and alongside innovations in synthesis and audio processing technology, often cited as one of the most important developments in electronic popular music. Within the United Kingdom, this became known as "krautrock". The term is problematic in several ways, as it was not only derived from a stereotyping slur (kraut is German for cabbage, used by the English-speaking world during the First and Second World Wars in reference to Germans) but was 
also used as an unhelpfully imprecise catch-all label for a diverse range of experimental rock and pop music from post-war West Germany. Furthermore, the notion of krautrock was derived from a British perspective on the German music scene. ${ }^{1}$ For example, Julian Cope comments that,

Amon Düül did not stay long, but they laid the beginnings of Krautrock with their music, and with one particular song ... translated as "Mama Düül and her Sauerkraut band Start Up!" With that title, the lazy British rock press at last had something to latch on to. (Cope 1996: 13)

In 1972 Ian MacDonald of New Musical Express ran a series of popular articles that first coined the term "krautrock" and were among the first articles to present this new German phenomenon to the United Kingdom. However, whilst MacDonald and other British critics such as Michael Watts, Dick Lawson, and John Peel encouraged a view of krautrock as some form of unified musical movement, musicians that were associated with the heading typically operated in comparative isolation from one another, especially those who were geographically disparate. ${ }^{2}$ In coverage from 1973, Jean-Pierre Lantin explained that due to the segregation of Berlin, it was "impossible for a band to follow a normal schedule or to play as much as two or three gigs a year in Berlin. So musicians play[ed] for each other, deepening their experiences, turning inward" (2009: 185-186). Indeed, despite their reputation as pioneers of the period, Edgar Froese of Berlin-based Tangerine Dream, for instance, reportedly first met Michael Rother of Düsseldorf-based Neu only recently in 2014 (Pearce 2014: web source).

Within West Germany, musicians were aware of the term "krautrock" but it was not in common use during the 1970s. Furthermore, Achim Reichel's sleeve notes to Musik von Harmonia showed particular animosity towards the heading:

People often mistakenly believed that Musik von Harmonia belongs to the category of so-called "Krautrock". Careless critics and reviewers tried to hide their lack of knowledge by pressing this ghastly label on the few artists that wouldn't behave like those stoned dancing bears. (Cited in Stubbs 2014: 6)

Labels such as "Berlin-school" and "Düsseldorf-school" have been applied to account for two prominent and generally coherent styles of krautrock, yet neither of the terms was in circulation during the seventies. ${ }^{3}$ However, an alternative label, kosmische music ("cosmic music"), emerged from within Germany itself in 1971 in the sleeve notes of Tangerine Dream's album Alpha Centauri, which predated the first uses of the "krautrock" label in the United Kingdom. Tangerine Dream's term gained further exposure the following year when the band's label of the time, Ohr Records, released a compilation of tracks by Klaus Schulze, Tangerine Dream, Ash Ra Tempel, and Popol Vuh under the title Kosmische Musik. ${ }^{4}$

In this article, kosmische musik is viewed as a musical style exemplified by Ohr's Kosmische Musik compilation and other studio releases in the early $1970 \mathrm{~s}$ by the artists featured on the compilation. Unlike krautrock as a whole, these musicians were mostly located in or near to Berlin, which offered some opportunity for creative exchange. ${ }^{5}$ The compilation also came at an important 
stage as musicians' began to establish their identities as groups or artists. Before he began a solo career in 1972, Klaus Schulze, for instance, had performed as a drummer with Psy Free, Ash Ra Tempel, and Tangerine Dream. Tangerine Dream's line-up of Edgar Froese, Christopher Franke, and Peter Baumann that lasted approximately four years from 1971-1975 was also one of the most stable periods of the band's early years.

The cultural significance of krautrock has been studied by a range of German scholars, ${ }^{6}$ though this research has infrequently explored aesthetic aspects of the music. The musical production of kosmische musik was especially important aesthetically, as musicians began to experiment with the possibilities of synthesizers such as the Moog Modular or EMS VCS3, sound processing effects, and tape-based recording technology. These technologies allowed musicians to manipulate or create new sounds, construct vast and unnatural acoustical spaces, and perform in ways that departed from normative popular music practices in West Germany and elsewhere. As Gilbert and Pearson (1999) argue in the context of dance music, we should be mindful of the interdependency between music, technology, society, and culture (see also Sterne 2003). In this article, I introduce several aspects of this interwoven techno-social context that frames the emergence of kosmische musik before I discuss three aesthetic characteristics in greater detail and explore their manifestation in Tangerine Dream's "Phaedra".

\section{Identities in music}

During the country's post-war recovery, Germany's role in the Second World War raised challenges for the new generation, particularly in relation to identity. In the field of social psychology, Hargreaves, Meill and MacDonald (2002) argue that music provides functional means of expressing and developing identity. In particular, the authors propose two general relationships between music and identity. The first, music in identities, refers to aspects of personal identity that are expressed or developed through music. Meanwhile, the second, identities in music, addresses aspects of identity in relation to music, such as the relationship between identity and roles of musicians or fans. Of these two relationships, the former is particularly pertinent in relation to the national identity of young Germans at the time.

Several writers have reported on the importance of krautrock and kosmische musik in relation to music and identity. Till Krause (2008) has emphasized that music played an important role in the formation of a new national identity for musicians in West Germany through what he has described as "aesthetic demarcation" from contemporaneous musical practices. This demarcation was particularly key, as musicians employed various approaches that were novel for the period and ultimately attractive, particularly to overseas audiences. These musical approaches included the use of chromaticism or untuned material, unconventional or ambiguous metre, and lengthy through-composed structures that were influenced by free jazz (see Wagner 2013: 123-155). Kosmische musik's aesthetic demarcation, though, most explicitly took place through its sound, which was achieved through musicians' approach to music production and the greater availability of electronics. 
Cope has suggested that many young German musicians were influenced by elektronische musik, a form of electronic art music, which was in itself an important aspect of the cultural identity of Germany. In particular, Cope writes that "Karlheinz Stockhausen is central to the entire history of Krautrock" (1996: 11) and highlights the role of his 1966 work Hymnen, which manipulates a selection of national anthems including the national anthem of Germany. Indeed, Stockhausen worked with the influential producer Conny Plank (Stubbs 2013: web source), and Czukay and Schmidt of the band Can (Barry 2014: web source). The influence of avant-garde composition is particularly important in relation to production strategies and the selection of sound sources for various krautrock musicians. Faust, for instance, became known for their onstage use of nonmusical sound sources such as power tools and a pinball machine (Gill 1997).

According to Cope, the proliferation of Anglo-American products and broadcasts during the 1960s had a considerable impact on the identity of young people in particular who were growing up in West Germany. He has also noted that the new national identity afforded by krautrock and kosmische musik was similarly important in how this younger generation of Germans identified themselves. Stubbs (2014) has subsequently argued that krautrockers pursued music-making that sounded different and new through the use of electronics to authenticate this burgeoning identity. Although both these accounts focus upon music, Applegate and Potter argue that "[t]he links between music and German identity can more often than not be traced to writers, thinkers, statesmen, educators, impresarios, demagogues, and audiences, but only occasionally to composers" (2002: 2-3). Therefore, before we address aesthetic aspects of kosmische musik, we should first consider the social surroundings at the time in which it emerged.

\section{Social surroundings}

In the decades that followed the Second World War, the population of West Germany increased significantly (Statistisches Bundesamt 2014: web source). Compared to the United States (Lahmeyer 2003: web source), German birth rates were modest, yet a considerable youth population, which grew amidst social and economic instability, formed during the 1960s. Although Nazi beliefs were delegitimized, for instance, the process of denazification was slow and continued for several years (Taylor 2012). The country's infrastructure remained reliant upon skilled professionals and so some previous supporters of the National Socialist German Workers' Party retained visibility in the public eye. The economic climate of the time was also particularly uncertain; in 1948, the United States of America instigated The Marshall Plan, which sought to promote the economic recovery of Western Europe following the Second World War. ${ }^{7}$ The initiative inspired hope for future prosperity in post-war West Germany, yet the country entered an economic recession in $1966 .{ }^{\circ}$ In response, the largest political parties of the time, the Sozialdemokratische Partei Deutschlands (SPD; Social Democratic Party of Germany) and Christlich Demokratische Union Deutschlands (CDU; Christian Democratic Union of Germany), unified. This unification gave the 
parties near-total control over the Bundestag (the local equivalent to a lower house of parliament).

Amid dissatisfaction with the state of German governance, particularly in relation to the coalition between the SPD and CDU, and fuelled by the increasing economic pressure on the working class by the 1966 recession, students rebelled with a series of demonstrations throughout major cities in West Germany during the late 1960s (Klimke 2010). ${ }^{9}$ These demonstrations began with non-violent action in 1966 against undemocratic university reforms. ${ }^{10}$ On June $2^{\text {nd }}$ the following year, however, a march organized by the Sozialistische Deutsche Studentenbund (SDS; Socialist German Student Union) in protest of the government's support for the Shah of Iran resulted in a violent engagement with the police and provoked a series of subsequent protests across the country. ${ }^{11}$

In addition to the social unrest in West Berlin and other major cities throughout West Germany, the disaffection of the youth, particularly amongst members of the SDS, was also reflected in the formation of communes such as Kommune 1 and Kommune 2 in 1967. Within such communes, a liberal ideology proliferated that was similar to the sexual revolution that occurred concurrently in the Western world, alongside growth in aspirations for freedom of speech and fair, democratic representation and governance. Notably, members of one such settlement adjacent to Munich came to perform in various configurations as the prominent krautrock act Amon Düül.

Several accounts have argued that the national youth's embrace of experimental music practices reflected not only the social issues felt throughout the country but also the sterile German popular culture at the time, as the thenrecent past made the continuation of previous musical practices unfeasible. Cunningham (2011: 45-47) and Kopf (2008: 144), for instance, have both emphasized that Kraftwerk, whose members were all the first generation to be born after the Second World War, sought to aesthetically distance themselves from the creative practices of the generation preceding them.

During the 1960s and 1970s, popular music throughout the country was dominated by schlager ballads and Anglo-American popular music. ${ }^{12}$ As popularized by figures such as Rex Gildo and Gitte Hænning, schlager was a conservative style of music that was seen by a disenfranchised young generation to be of little cultural merit. The songs often expressed somewhat insipid and nostalgic themes with a dubious optimism that ultimately showed an unease with which both musicians and the wider public reflected on life at a time of ongoing economic and social tensions. Kosmische musik's departure from schlager and the conventions of most Anglo-American popular music exemplifies the action of music in identities, as it afforded German musicians higher subcultural capital and a sense of nonconformist authenticity.

\section{The cosmic world of electronics}

The social context of West Germany following the Second World War provides an important backdrop to the emergence of new musical styles though, as Hargreaves and North (1999) argue, the social role of music is also affected by the possibilities of playback and production technology available to listeners and 
producers. Kosmische musik, for instance, could not have attained the same listenership without the possibility of international distribution as phonographic records. Meanwhile, synthesis and sound processing technologies supported a sonic aesthetic that incorporated procedures such as multitracking or tape manipulation, which could not have been achieved in real time.

In a discussion of the interplay between music and wider technological and cultural discourses, Timothy Taylor (2011) has explained that optimism and fascination with technology spread throughout the Western world following the war and led to an elevated position of the sciences. Collins, Schedel, and Wilson (2013) have also highlighted the televised moon landing of 1969 in a timeline of electronic music because of the curiosity that it inspired amongst musicians and the general public. The authors have also stressed the importance of an alternative timbral pallet of synthesizers and electronics in broadcast media at the time, and the supernatural and unearthly connotations of synthesis and sound processing devices in science fiction soundtracks.

The interest that grew in new music technology after the war and the space race was reflected by the intrigue that German musicians showed in the cosmos. John Wienzierl of Amon Düül II has commented on the aesthetic departure from overseas musical practices, and explained "we tried not to be Anglophonic [and] we tried not to be German so space was one solution" (BBC 2009: 05:59-06:08). The role of electronic music technology in the conception of this new, cosmic music is perhaps unsurprising. Thom Holmes, for instance, suggests that the "essence of electronic music is its disassociation with the natural world ... Having little basis in the object world, electronic music becomes the pulse of an intimate and personal reality for the listener. Its source is mysterious" (2008: 123). The evocation of mysterious, unknown worlds to which Holmes alludes is particularly fitting for a society intrigued by the cosmic.

Stubbs (2014: 25) indicates that the breadth of wealth was wide amongst young German musicians during the 1970s. This is particularly pertinent given the economic instability of the late 1960s in West Germany. Accordingly, musicians without access to more advanced and expensive audio technologies made extensive use of effects processing, especially the use of frequency filters and tape editing. ${ }^{13}$ In time, analogue synthesizers came to perform an increasingly important role in the construction of kosmische soundscapes. Indeed, whilst expressing a similar sentiment to Holmes, lan MacDonald's coverage claims "[i]n Germany the synthesizer is king, but it is employed mainly for its obvious otherworldly capacities as a mood-setter" (1972a: web source). With this, MacDonald emphasizes the aesthetic importance of the synthesizer and its otherworldly connotations. ${ }^{14}$

Pinch and Trocco write that EMS synthesizers were marketed aggressively to schools, academics, and kosmische musicians through demonstrations for "a mixture of professors and a few sort of elite pop stars" such as "Tangerine Dream, Klaus Schulze, those sorts of people" (2002: 297). Moog synthesizers were also commercially available internationally; the widow of Florian Fricke (Popol Vuh) has reported that he was one of the first Moog owners in Germany (Waldthausen 2013: web source), although synthesizers remained prohibitively costly for many of Fricke's peers for several years. ${ }^{15}$ Hence, whilst MacDonald's coverage highlights the synthesizer for its otherworldly connotations, it does not address the 
important role of audio processing, such as distortion, filtering, and phasing effects, that were integral to kosmische musik's production. These technologies all share the possibility to create soundscapes with little or no correspondence with unmediated acoustical counterparts and hence could also be used to evoke the "otherworldliness" MacDonald observes of the synthesizer.

Several important commonalities can be observed throughout the Kosmische Musik compilation in terms of production strategies and the use of recording and sound processing technologies as tools to conceive music. Notably, this marked some of the earliest instances in the context of West German popular music of what Eno (2004) describes as the use of the recording studio as a compositional tool (see also Moorefield 2005). Three common aspects of production in particular appear to suggest the establishment of a kosmische musik aesthetic: the creation of large, unrealistic, and non-static acoustical spaces; the manipulation or generation of sounds with little or no correlation with acoustic instrumentation; and, an increased emphasis on timbral shaping of sounds, which correspond in several cases with greater use of technology to trigger them.

\section{Acoustical space and phonographic staging}

In their study of spatialisation within recorded music, Brøvig-Hanssen and Danielsen (2013) propose that virtual spaces may appear surreal to listeners if they do not correspond to actual spaces or to normative production strategies that have become naturalized. In the 1970s, the availability of stereophonic production and audio processing effects offered the manipulation of timbral, temporal, and spatial parameters that Lacasse (2000) has termed "phonographic staging" provided means to construct such surreal phonographic spaces. To describe the construction of space in recorded popular music, Allan Moore proposes a soundbox model, which accounts for the panorama, perceived distance, perceived height, and temporal continuity of sound sources. As he explains, throughout "the 1960s, producers and engineers gradually came to adopt a normative positioning of sound sources within the soundbox, a positioning that tends to remain stable throughout a track" (2012: 32). In earlier writing, Dockwray and Moore (2010) account for the establishment of this normative configuration of the soundbox between 1965-1972 and demonstrate its increasing use amongst a sample set of 1,000 tracks, which include charting Anglo-American works and other international repertoire. The manipulation of phonographic acoustical space in ways that departed from both actual spaces and Dockwray and Moore's naturalized normative position provided an especially common means by which kosmische musik production was distinguished from contemporaneous German popular music.

Throughout the Kosmische Musik compilation and related work, tracks principally exemplify expansive soundboxes through the application of wide stereo panning and simulated reverb. Furthermore, changes in reverb, delay, and panning parameters throughout a track suggest that they are used as creative effects, which demonstrates the use of the recording workplace in an aesthetic capacity beyond the more common use of reverb and delay to simulate a stable acoustical space. The excerpt of Klaus Schulze's "Ebene" on the Kosmische Musik 
compilation, for example, implies a large acoustical space through wide panning and use of reverb. However, manipulation of autopanning and delay parameters throughout the track suggests an aesthetic role beyond the fabrication of a stable acoustical space. A similarly large soundbox is evoked by Tangerine Dream's "Origin of Supernatural Probabilities", which also makes liberal use of reverb, tremolo, and panning effects to construct an otherworldly space that transforms over the course of the track. The aesthetic uses of spatial effects and mobility of phonographic staging by kosmische musicians demonstrates a departure from the normative configuration of the soundbox in schlager, and from the normative position identified by Dockwray and Moore in the Anglo-American works that they profile.

\section{Sonic design and landscape}

As reception testing indicates that source identification plays a crucial and prevalent role in musical listening alongside perceptions of acoustic character (Dibben 2001), we should also consider the use of sound processing and synthesis technology. Throughout the Kosmische Musik compilation, sounds are used that do not appear to originate from acoustical sources, which further contributes to the music's surreal or otherworldly character.

In the field of electroacoustic music, Trevor Wishart (1986) has coined the term landscape to refer to the sound sources imagined from listening to a recording. During the 1970s, German schlager normatively consisted of a singer, bass, drum kit, and harmonic instruments such as guitars, acoustic piano, or string section. Generally, then, schlager evoked landscapes of musicians playing acoustic instruments. In contrast, kosmische musik generally omitted the voice other than as a textural effect and was explicitly conceived within the recording workplace through the clear use of electronics. Hence, its landscapes did not correspond to contemporaneous live popular music in the country. Indeed, Hegarty's (2007: 106) investigation of noise and music highlights kosmische musik and the broader krautrock repertory for the musical incorporation of noise and timbres that were unconventional for the time. The Ohr compilation, for instance, featured the use of bass guitars, electric guitars, synthesized elements, a Mellotron-like choir organ on Popol Vuh's "In Den Gärten Pharaos", and acoustic percussion. Other recordings made occasional use of additional acoustic instruments, which were often processed in transformative ways that challenged source identification. Klaus Schulze's two solo contributions to the compilation, "Ebene" and "Land", for instance, incorporated aggressive frequency filtering of an orchestra, and modulated frequency filtering, phaser, and delay effects applied to a multitracked organ, respectively. ${ }^{16}$

Commensurate with the use of electronic sonic manipulation and landscapes that were unusual for the time in West Germany, kosmische musik also embraced the use of glissandos and sounds that were not tuned to particular pitches, in addition to performance techniques that were unconventional in relation to schlager. This can be heard especially in electric guitar passages. Ash Ra Tempel's Schwingungen album, which was edited to approximately ten minutes on the Ohr compilation for instance, featured a variety of normative guitar strumming as well 
as rapid tremolos and large glissandos, processed using distortion and phaser effects, whilst Tangerine Dream's "Geburt" made extensive use of glissando in the electric guitar and extended cello performance techniques.

\section{Performative agency}

Alongside the prominent use of electronic sound sources, kosmische musik was less reliant upon the conventional role of the performer. In the field of electroacoustic music, Denis Smalley (1997) outlines a typology of gestural activity discernible within an instrumental articulation and employs the term "surrogacy" to refer to the separation of sound from its original resonant source or gestural cause such as the striking of a piano or bowing of strings. Whereas most other popular music relied upon the gesture of a performer, the utility of electronics within Ohr's Kosmische Musik release afforded greater degrees of surrogacy, which contributed to non-natural landscapes. With the introduction of sequencer modules and, subsequent increased availability of drum machines during the 1970s, it was also possible to automate performances, which resulted in not only gestural surrogacy but also the reduction of performative agency - that is, the influence of musicians over details of a performance - for these devices allowed mechanical realisations of automated performances and were capable of repetition far beyond the stamina of corresponding human performers. As Thom Holmes (2008: 123) argues, a "fundamental trait" of electronic music is that it "does not breathe: it is not affected by the limitations of human performance".

Ash Ra Tempel's "Traummaschine", Tangerine Dream's "Sunrise in the Third System", and Klaus Schulze's "Ebene" each employed drones and electronically triggered synthetic textures. Yet, we might regard the reduced agency of a performer in making sound as a shift towards more explicit production practices, as musicians and recordists would often play important roles in sound-shaping. The performative role of the recordist is highlighted by Samantha Bennett in her analysis of the UK punk album Never Mind the Bollocks, Here's the Sex Pistols and its recordists' use of gesture: "the intentional and sonically discernible decisions made by the recordist, for example, spatial, volume, or frequency movements occurring during the course of the recording" (Bennett 2015: 470). This understanding of gesture can be heard in the manipulation of low frequency oscillators affecting amplitude and the cut-off frequency of a low-pass filter in Klaus Schulze's "Land" from approximately 05:00-08:50, the more gradual panning and use of fades in the guitar line of Tangerine Dream's "Origin of Supernatural Probabilities" throughout the opening two minutes of the excerpt on the compilation, and the moving panning of the synthesizer in "Sunrise in the Third System" from 02:00-02:40.

The reconfiguration of performative agency from familiar performance techniques towards the more mysterious operations of the recording workplace was also reflected in the visual aesthetics of accompanying album packaging, for it was somewhat rare for performers to feature on the covers of kosmische records. Throughout the 1970s no studio album releases by Tangerine Dream, Ashra, nor Popol Vuh showcased the performers on cover artwork. ${ }^{17}$ 


\section{Tangerine Dream, "Phaedra"}

The approaches to acoustic space, sonic design, and performative agency summarized above continued in several solo works following the release of the Kosmische Musik compilation, which suggests that they became normative elements of a kosmische aesthetic. Between 1970-1973, Tangerine Dream released four albums in association with Ohr Records that, as indicated above, were particularly important in the development of this aesthetic. In 1973, however, the band signed to the fledgling Virgin Records, which led to a fruitful relationship lasting until 1983. As Simon Reynolds has described, this was a particularly opportune time for the label to sign the band:

Virgin Records, in those days a mail-order company specialising in import albums from Europe, shifted more than 15,000 Tangerine Dream albums through the post. Richard Branson realised the band were perfect candidates to launch his record label and shape a distinct identity for it. (Reynolds 2007: web source)

Released in 1974, Tangerine Dream's album Phaedra was the first record that the band released as part of their new partnership with Virgin. Buoyed by the success of the record, Virgin subsequently embarked on an aggressive commercial strategy that secured more than twenty releases from German bands in the next eight years.

The album itself is of particular significance, as it marked the band's first entry on the UK albums chart at number 15 (Official Charts Company 2015: web source), and the US Billboard 200 at number 196 (Billboard 1974), yet critical responses varied. For David Stubbs:

The scampering sequencers that dominated Phaedra in 1974 were an indication that Tangerine Dream were now voyaging in one direction, never looking back to the nebulous futures they would prefigure on Zeit. It's a decent album but listening to it following Zeit and Atem can only be compared to the experience of being in a darkened room and your eyes accustoming themselves to what had seemed like enigmatic shapes, now revealed as ordinary household objects... (2014: 307-308, italics in original)

Whilst Stubbs appears to see Phaedra as a creative departure from their previous work, Mark Prendergast's favourable review of the title track brings it clearly into association with kosmische musik and its themes of otherworldliness; it,

conveyed feelings of the cosmos, of giant suns exploding, of huge ocean movements, of mythological lands, of eddies and drifts. Layer upon layer of futuristic sounds piled one on top of the other until the whole thing climaxes in some interstellar void. (2013: web source)

As with the band's earlier work, the album was created using a moderate collection of chiefly electronic instruments, which included a Mellotron, guitar, bass, EMS VCS3 synthesizers, electric piano, and flute, in addition to a new Moog modular synthesizer that Franke bought after he experimented with Florian 
Fricke's Moog during the recording of Zeit (Prendergast 1994: web source) and accompanying sequencer module. This instrumentation was supplemented by a variety of reverberation, distortion, phaser, and frequency-filtering effects heard during their previous work in association with Ohr. Throughout the title track, several observations suggest a continuation of the kosmische production aesthetic.

"Phaedra" can be divided into three key sections of musical discourse. ${ }^{18}$ The first, which lasts approximately 04:38, sets the general mood of the piece through the development of a synthetic landscape and the introduction of melodic elements. The second, which runs between 04:38-10:18, is constructed largely from overlaid ostinato patterns and manipulation of sequenced material. Finally, from 10:18, the last major section features no explicit rhythmic elements in favour of mostly thinner textures and a greater focus on harmonic movement. Following the musical conclusion of the third section (16:36), an ambient recording of children's voices is also included on the album as a bridge between "Phaedra" and the following track.

Throughout the first section of the piece, the sound sources are entirely generated using electronic instruments. The section begins with a series of synthesized elements staged within a wide and deep soundbox. Following an initial growth in texture using multiple sequenced synthesizer lines treated with reverb and delay, the lowest slows to become a bass line that establishes a tonal centre and sense of 4/4 metre. Between 02:27 and approximately 02:36, the pitch of the sequenced synthesizer line is gradually raised by approximately a semitone and a low pass filter is also raised to add brightness. Thereafter, a Mellotron choir is added to the soundbox and the lead synthesizer tentatively enters, though it is not until 03:37 that a clear melodic line enters, which pivots about a D as the cutoff of a resonant low pass filter is modulated.

This opening section demonstrates clear affinity with the normative approaches to acoustical space, sonic design, and performativity agency reflected by the band's kosmische musik contemporaries. For the most part, the acoustical space implied by the phonographic staging of instruments is particularly large, yet the inconsistent application of reverberation and delay effects renders it an explicitly studio-constructed acoustical space. The bell-like sound, for instance, which likely derives from the electric piano, is processed using moderately long, bright reverb with lengthy pre delay, whilst the sequenced synthesizer appears dryer but with an added delay effect. ${ }^{19}$

Several of the sound sources during the opening 04:38 are also distant gestural surrogates. This can be heard in the Mellotron and lead synthesizer lines, though both still afford identification with a human performer. Conversely, the sequencer and the several extended/drone textures are rendered without both identifiable acoustic sources and gestural causes. Nevertheless, gesture and agency can be clearly discerned in the shaping of sound through details, such as the tuning of the sequenced synthesizer's pitch and the speed of the sequencer module's pattern, fades in amplitude, and the sweeping filter on the melody line. Alongside this performative role in sound-shaping and incoherent acoustical space, the opening section of the track creates a landscape with little correspondence to recognisable acoustical sound sources.

The second section is marked by a picked bass guitar that begins at 04:36 with added delay and some manipulation of the ratio between dry and reverberated 
signal. Following several repetitions of its rudimentary pattern, the sequenced synthesizer returns in its place. Both are overlaid with Mellotron chord clusters that swell in amplitude and appear to move in terms of proximity and stereo placement within the soundbox whilst processed by a resonant sweeping lowpass filter. The texture gradually thickens with additional sequenced elements and a flute manipulating a similar ostinato until at 06:27, the texture thins and the lowest pitched sequenced synthesizer begins to pan between the horizontal extremes of the soundbox. Additional reverb and distortion is added here to breathy flute trills. The sequenced synthesizer is later doubled once again by a similar pattern on electric guitar, though soon begins a gradual widening of pitch range as the soundbox becomes increasingly saturated with reverberation. From approximately 09:26, this sequenced synthesizer line begins to ascend gradually until reaching a fifth higher and the Mellotron choir reappears as the track moves to the next section.

Whereas the landscape of the first section is constructed entirely from electronic sound sources, the introduction of the electric guitar and flute in this second section is more recognisable, though both are explicitly transformed by audio effects. The rendition of the guitar and flute passages also introduces clearer association with instrumental performers, although both reflect the behaviour of the sequenced synthesizer lines through the manipulation of repeated ostinatos. Indeed, the overblown flute trills fulfil a principally textural role that is enhanced by the amount of reverberated signal, and changes in its amplitude that may result from the record's mixing process. Once again, performative agency is also discernible from details such as the upward tuning of the sequenced synthesizer line and the manipulation of its pattern, and in aspects of phonographic staging such as the manipulation of panning, volume, filter cut off frequency, and the amount of delayed/reverberated signals.

A metric modulation at 10:18 marks the beginning of the third section, at which point the pattern length and speed of the sequencer decrease to suggest a shift from approximately $150 \mathrm{bpm}$ to $225 \mathrm{bpm}$, though the sequenced synthesizer quickly recedes as its amplitude and the ratio between dry and reverberant signal decrease, leaving a sparse soundbox with no clear metre, pulse, nor tonality. Rather, a series of chorused metallic gestures enter alongside a swelling, unpitched drone. At 11:10, the chime-like electric piano returns with atonal broken chords before additional synthesizer textures are added using VCS3 synthesizers to create repeated gestures that waver in frequency, as though emulating a bird call, and a bed of noise-based texture. From approximately 12:04, the Mellotron returns to re-establish a tonal basis as the VCS synthesizers recede within the soundbox and over the course of the two minutes that follow, the texture begins to thicken once again as the electric piano and elements from the first section return. At 14:27, a prominent string Mellotron line and electric piano enter, which draws the track to a close using slow chord progressions towards a tonally-ambiguous dyad of $\mathrm{A}$ and $\mathrm{E}$.

As before, the section evokes an obscure landscape of sound sources derived from electronics, though with a greater emphasis on noisy and unpitched materials. Similarly, although the soundbox is notably sparser throughout much of this third section, the phonographic staging once again suggests a large, evolving acoustical space. Overall, the track's acoustical space and landscape of electronic 
sound sources, manifestation of gesture in the manipulation of effects, and lessened reliance upon instrumental performance brings the track in clear correspondence with kosmische production aesthetics.

\section{Conclusion}

Kosmische musik emerged in the late 1960s amid an unstable social and cultural climate in West Germany. In the wake of the country's then-recent wartime past, the post-war generation were born into a society whose previous culture had been rendered largely illegitimate, the support provided from the country's social infrastructure was limited, and students engaged in active protest in response to waning democracy. Accordingly, popular music within the country was dominated by Anglo-American songs and schlagers, which portrayed an optimistic and conservative outlook that offered a degree of escapism to an older generation but failed to represent the beliefs and values of significant numbers of young Germans. Earlier interest in the prospects of new technology and outer space was invigorated on an international scale following the Second World War, encouraging exploration of the creative possibilities of electronic music technology. Both aspects of this techno-social context of West Germany can be seen as contributing factors to the emergence of musical practices that were aesthetically demarcated from both the illegitimized musical artefacts of pre-war Germany and popular music of the period.

Although the idea of krautrock as a musical movement was largely a British construction propagated by journalism and music imports rather than a coherent musical style in itself, Ohr Records' curation of the Kosmische Musik compilation brought together works that featured a clear musical and phonographic aesthetic characterized by three particular aspects of production: the creation of mutable acoustical spaces that could not naturally occur; the generation of sounds, which did not resemble recognisable acoustical sources; and, the use of new performance strategies afforded by electronic music technology. These aspects formed the basis of a new musical formation in West Germany and marked a crucial departure from normative popular music practices in the country. Although some commonalities can be observed between kosmische musik and innovative examples of Anglo-American popular music that incorporated the use of similar production strategies, the former was conceived as a means of aesthetic demarcation from mainstream Anglo-American popular music available in West Germany.

However, other music productions from the so-called krautrock period exhibited different stylistic traits that corresponded closer with Anglo-American rock music, even though some overlap can be observed with characteristics of kosmische musik. The reconfiguration of performative agency, for instance, is clearly reflected in the music of Kraftwerk and their cyborgian vision of the manmachine. This reconfiguration can also be connected with the mechanistic repetition of the so-called "motorik beat", which is found especially prominently throughout Klaus Dinger's work with Neu (see Brain 1973a, 1975) and Harmonia (Brain 1974a, 1974b, 1975), which Kopf (2008) regards very clearly in terms of the Autobahn and industrialisation. Similarly, many krautrock musicians departed 
from the acoustic landscapes of schlagers with harsher, distorted colours that often originated from acoustic instruments or sources. Furthermore, whilst kosmische musik was especially creative with phonographic staging, novel approaches to acoustical space and phonographic staging can also be occasionally found in tracks such as Neu's "Hallo Excentrico" (Brain 1973b), which relies primarily on the manipulation of tape speed as groups of sounds navigate the stereo space and reverberation is manipulated.

The impact of kosmische musik, particularly the early work of Tangerine Dream and Klaus Schulze, is highlighted by Reynolds (2007: web source) as a key aspect in the development of popular electronic music preceded the work of other prominent figures such as Jean Michel Jarre and Tomita. Several kosmische musicians also collaborated with foreign artists; for example, Cluster worked with British producer Brian Eno, and Klaus Schulze produced for the Japanese Far East Family Band (the start of Kitarō's the musical career) in the mid-1970s. This influence also extends to contemporary artists such as the French electronic band M83 who regularly cite the importance of kosmische musicians (Bakare 2016: web source). With this in mind, further attention may be directed from a sound studies perspective to kosmische musik in relation to electronic music making elsewhere from the 1970s and the effects of technology and culture at the time upon musical meaning.

The above discussion has briefly considered kosmische musik's aesthetic demarcation from popular music elsewhere as a means of creating and expressing a new national identity for young Germans. Further research is required to comprehensively account for the role of kosmische musik in relation changing identity and how personal identities were shaped by the cultural and social roles of young musicians. Hargreaves and North (1997) argue for the consideration of the effects of social environments upon the reception of music, inviting future investigations that may consider the social contexts in countries that heavily imported kosmische musik records as well as the contributions of kosmische musik to identities of listeners living abroad.

\section{Endnotes}

${ }^{1}$ See also Morawietz (quoted in Stubbs 2014: 39).

2 Although MacDonald's commentary coined and popularized the term "krautrock", earlier coverage by Dick Lawson (1970) also suggests it was a wider trend throughout West Germany (see also Lantin 2009).

${ }^{3}$ Boehme (2014) observes that this nomenclature is geographically misinformed, as Can, for instance, emerged from Cologne yet are often associated with the Düsseldorf-school.

${ }^{4}$ A label of the same name was also subsequently established by Ohr's founder, though this was short-lived.

${ }^{5}$ Between 1968-1969, the Zodiac Free Arts Lab in Berlin, formed by Conrad Schnitzler and Hans-Joachim Roedelius who later formed Kluster, provided an important opportunity for Berlin-based musicians to share their music. Klaus Schulze also reportedly bought his first Moog from Florian Fricke (Stubbs 2014: 362), who performed on Tangerine Dream's Zeit in 1972. 
${ }^{6}$ See, for instance, Leitner (1983), Rauhut (1993, 2002), and Hintze (2000) on the relationship between East Germany and popular music; Dedekind (2008) on krautrock in relation to LSD and psychedelic subcultures; and, Siegfried (2008) on music in relation to social change from the 1960s.

7 The Marshall Plan was effective for four years from April 1948, during which time the United States of America pledged significant financial support and legislative changes to encourage trade and industrial development across Western Europe. Recent writing on the plan by Schain (2001) and Mills (2008) both provide instructive introductions and evaluations of its impact.

${ }^{8}$ West Germany was similarly affected in 1973 by the recession across Europe, which had a further destabilizing influence over the country's politics (Wollmann 2000).

${ }^{9}$ As observed by Colin Barker, this situation was not specific to Germany, as the "1960s and early 1970s were notable for the rise and spread of student movements across many parts of the industrialized world" (Barker 2008: 43).

${ }^{10}$ The first such protest was a sit-in organized at der Freie Universität Berlin ("the Free University of Berlin") in June. Bergmann (quoted in DGDB n.d.: web source) suggests that this was principally a response to the lack of democratic student representation, rather than in objection to the reforms themselves, which were taking place.

11 Reportedly, a group protesting governmental support for the Iranian monach, Mohammad Reza Pahlavi, held a demonstration during his visit to the Deutsche Oper (the West Berlin opera house). Following rising tensions between the demonstrators and Iranian secret service, police intervention led to the shooting of Benno Ohnesorg, a German student whose death and the subsequent acquittal of his shooter spurred action elsewhere (Bezirksamt Charlottenburg-Wilmersdorf 2008: web source). A multimedia history of this and related events during the period is maintained at http://www.the-berlinwall.com. Klimke (2010) also provides a more detailed discussion of the SDS' political activities and provides a comparison with contemporaneous activities in the United States of America.

${ }^{12}$ Schlager (loosely translated as "hit-songs") was a form of popular music that resembled light-hearted entertainment music popularized earlier in German cinema. As a musical style, schlager was characterized by sentimental lyrical matter and crooning vocal style alongside simple diatonic harmonic patterning.

${ }^{13}$ These were both integral in creating albums such as Klaus Schulze's debut Irrlicht (Ohr Records 1972) album and Tangerine Dream's Alpha Centauri (Ohr Records 1971), which are derived from the manipulation of principally acoustical sound sources.

14 MacDonald contrasts this, for instance, with what he calls "the percussive and humorous role it assumes now and then in the hands of Roxy Music's brilliant Eno" (1972a: web source).

${ }^{15}$ Fricke reportedly acquired his Series III modular synthesizer in 1969 (Bearman 2008: web source).

${ }^{16}$ The relevant filtering effects used in kosmische musik involved reducing the amplitude of frequencies above, in the case of low-pass filters, or below, in the case of high-pass filters, a cut off frequency. Phaser effects create a series of troughs in the frequency spectrum of a signal, which sweep up and down at a given rate. Delay effects involve delaying an audio signal that is then mixed with the original and often fed back into the delay chain to simulate an echo. 
17 This is reflected broadly by krautrock musicians. Tellingly, the front cover of Can's album Ege Bamyasi (1972), which comes a decade after Andy Warhol's famous Campbell's Soup Cans, simply displays a tin can, speaking to the distancing of the band's image from the music whilst perhaps also offering a commentary on the commoditisation of their music.

${ }^{18}$ My analysis refers to the 1985 CD release of Phaedra. The 1995 remastered recording is now the principal version in distribution, which omits the children's voices at the end of the original and does not correspond exactly to the same timings of the original release but retains the features highlighted in the analysis.

${ }^{19}$ In the context of reverb effects, pre-delay describes the time between an initial sound (or early reflections) and the start of simulated reflections, whilst the reverb time describes the length taken for these reflections to fall in amplitude by $60 \mathrm{~dB}$. During the opening section, the mix between reverberated and dry electric piano signal changes, although the use of reverb is clear on the notes following the delay effect.

\section{References}

\section{Bibliography}

Applegate, C. and Potter, P. 2002. Music and German National Identity. Chicago, IL: University of Chicago Press.

Bakare, L. 2016. M83: "Tangerine Dream are the reason I'm obsessed with synthesisers". The Guardian. 16 June.

https://www.theguardian.com/music/2016/jun/16/m83-anthony-gonzalez-topfive-electronic-albums-tangerine-dream-snthesisers; Accessed: 17 August 2016.

Barker, C. 2008. Some Reflections on Student Movements of the 1960s and Early 1970s. Revista Crítica de Ciências Sociais 81: 43-91.

Barry, R. 2014. A Different World: Holger Czukay on Canaxis 5. The Quietus. http://thequietus.com/articles/14686-can-canaxis-holger-czukay-interview; Accessed: 19 March 2016.

Bearman, G. 2008. The Transcendent Music of Popul Vuh. Perfect Sound Forever. http://www.furious.com/perfect/populvuh.html; Accessed: 16 March 2016.

Bennett, S. 2015. Never Mind the Bollocks: A Tech-Processual Analysis. Popular Music and Society 38(4): 466-486.

Bezirksamt Charlottenburg-Wilmersdorf. 2008. Infotafel zur Erschießung Benno Ohnesorgs am 2. Juni 1967 (deutsch und eng/isch). http://www.berlin.de/bacharlottenburg-wilmersdorf/ueber-den-bezirk/geschichte/gedenktafeln/mdbbennoohnesorginfotafel.pdf; Accessed: 8 August 2016.

Billboard. 1974. Top LP's \& Tape. Billboard. 13 July: 50-52.

Boehme, T.C. 2014. "The Echo of the Wall Fades": Reflections on the "Berlin School" in the Early 1970s.. In M. Gandy and B. Nilsen Eds. The Acoustic City. Berlin: Jovis: 84-90. Translated by S. Jasper.

Brøvig-Hanssen, R. and Danielsen, A. 2013. The Naturalised and the Surreal: Changes in the Perception of Popular Music Sound. Organised Sound 18(1): 71-80.

Collins, N. et al. 2013. Electronic music. Cambridge: Cambridge University Press.

Cope, J. 1996. The Krautrock Sampler. Great Britain: Common Era. Second edition. 
Cunningham, D. 2011. Kraftwerk and the Image of the Modern. In S. Albiez and D. Pattie Eds. Kraftwerk: Music Non-Stop. New York and London: Continuum: 44-62.

Dedekind, H. 2008. Krautrock: Underground, LSD und Kosmische Kuriere. Höfen: Hannibal.

DGDB. n.d. Das "Sit-in" als Methode der Universitätsreform (22 Juni 1966). Dokumente - Die Rebellion einer Generation. http://germanhistorydocs.ghidc.org/sub_document.cfm?document_id=891; Accessed: 11 August 2016.

Dibben, N. 2001. What Do We Hear, When We Hear Music? Music Perception and Musical Material. Musicae Scientiae 5(2): 161-194.

Dockwray, R. and Moore, A.F. 2010. Configuring the Sound-Box 1965-1972. Popular Music 29(2): 181-197.

Eno, B. 2004. The Studio as a Compositional Tool. In C. Cox and D. Warner Eds. Audio Culture: Readings in Modern Music. New York and London: Continuum: 127-130.

Gilbert, J. and Pearson, E. 1999. Discographies: Dance Music, Culture, and the Politics of Sound. London and New York: Routledge.

Gill, A. 1997. Faust: Krautrock. MOJO, April. http://www.rocksbackpages.com/Library/Article/krautrock; Accessed: 31 January 2016.

Hargreaves, D.J. Meill, D., and MacDonald, R.A.R. 2002. What Are Musical Identities, and Why Are They Important? In R.A.R. MacDonald, D.J. Hargreaves and D. Miell Eds. Musical Identities. Oxford: Oxford University Press: 1-20.

Hargreaves, D.J. and North, A.C. 1997. The Social Psychology of Music. Oxford: Oxford University Press. 1999. The Functions of Music in Everyday Life: Redefining the Social in Music

Psychology. Psychology of Music 27(1): 71-83.

Hegarty, P. 2007. Noise/Music: A History. New York: Continuum.

Hintze, G. 2000. Rocklexikon der DDR. Berlin: Schwarzkopf \& Schwarzkopf.

Holmes, T. 2008. Electronic and Experimental Music: Technology, Music, and Culture. London and New York: Routledge. Third edition.

Klimke, M. 2010. The Other Alliance: Student Protest in West Germany and the United States in the Global Sixties. Princeton, NJ: Princeton University Press.

Kopf, B. 2008. The Autobahn Goes on Forever. In R. Young Ed. Undercurrents: the Hidden Wiring of Modern Music. London and New York: Continuum: 141153.

Krause, T. 2008. "Amerrrika Ist Wunderrrbarrr": Promotion of Germany through Radio Goethe's Cultural Export of German Popular Music to North America. Popular Music 27(2): 225-242.

Lacasse, S. 2000. "Listen to My Voice": The Evocative Power of Vocal Staging in Recorded Rock Music and Other Forms of Vocal Expression. http://www.mus.ulaval.ca/lacasse/texts/THESIS.pdf; Accessed: 8 November 2013.

Lahmeyer, J. 2003. United States of America: Population Growth of the Whole Country. http://www.populstat.info/Americas/usac.htm; Accessed: 3 January 2014. 
Lantin, J.-P. 2009. At last: German Rock Has Arrived! In Krautrock: Cosmic Rock and Its Legacy. London: Black Dog Publishing: 184-189. Translated by C.

Kinsella.

Lawson, D. 1970. Macht Das Ohr Auf. Friends. 10 July: 27.

Leitner, O. 1983. Rockszene DDR: Aspekte einer Massenkultur im Sozialismus.

Reinbek bei Hamburg: Rowohlt.

MacDonald, I. -

1972a. Krautrock: Germany Calling. New Musical Express, 9 December.

http://www.rocksbackpages.com/Library/Article/krautrock-germany-calling;

Accessed: 23 August 2014.

1972b. Krautrock: Germany Calling \#2. New Musical Express, 16 December. http://www.rocksbackpages.com/Library/Article/krautrock-germany-calling2; Accessed: 23 August 2014.

1972c. Krautrock: Germany Calling \#3. New Musical Express, 23 December. http://www.rocksbackpages.com/Library/Article/krautrock-germany-calling3; Accessed: 23 August 2014.

1972d. Late Arrivals. New Musical Express, 23 December.

http://www.rocksbackpages.com/Library/Article/krautrock-germany-calling3; Accessed: 23 August 2014.

Mills, N. 2008. Winning the Peace: The Marshall Plan and America's Coming of Age as a Superpower. Hoboken, NJ: John Wiley \& Sons.

Moore, A.F. 2012. Song Means: Analysing and Interpreting Recorded Popular Song. Aldershot: Ashgate.

Moorefield, V., 2005. The Producer as Composer Shaping the Sounds of Popular Music. Cambridge, MA: MIT Press.

Official Charts Company. 2015. Phaedra | full Official Chart History | Official Charts Company. Official Charts. http://www.officialcharts.com/search/albums/phaedra/; Accessed: 28 March 2016.

Pearce, I. 2014. In Photos: Tangerine Dream, Michael Rother (NEU!/Harmonia) \& Dieter Moebius. The Thin Air. http://thethinair.net/2014/04/in-photos-tangerinedream-michael-rother-neuharmonia-dieter-moebius/; Accessed: 10 August 2014.

Pinch, T.J. and Trocco, F. 2002. Analog Days: The Invention and Impact of the Moog Synthesizer. Cambridge, MA: Harvard University Press.

Prendergast, M.J. -

1994. Tangerine Dream: Changing Use of Technology, Part 1: 1967-1977.

Sound on Sound.

https://www.soundonsound.com/sos/1994_articles/dec94/tangerinedream.ht ml; Accessed: 19 March 2016.

2013. Tangerine Dream: Remembering the Dream. Ambient Century. http://www.ambientcentury.co.uk/classic-author-writings.html; Accessed: 15 March 2016.

Rauhut, M. -

1993. Beat in der Grauzone: DDR-Rock 1964 bis 1972: Politik und Alltag.

Berlin: BasisDruck.

2002. Rock in der DDR: 1964 bis 1989. Bonn: Bundeszentrale für politische Bildung. 
Reynolds, S. 2007. Kings of the Cosmos. The Guardian. 22 April.

http://www.theguardian.com/music/2007/apr/22/features.musicmonthly7. Accessed: 15 March 2016.

Schain, M. 2001. The Marshall Plan: Fifty Years After. New York: Palgrave Macmillan.

Siegfried, D. 2008. Time Is on My Side: Konsum und Politik in der Westdeutschen Jugendkultur der 60er Jahre. Göttingen: Wallstein Verlag.

Smalley, D. 1997. Spectromorphology: Explaining Sound-shapes. Organised Sound 2(2): 107-126.

Stark, J. 2006. "Tief im Westen": vom Krautrock bis zur Neuen Deutsche Welle. In B. Hammerschmitt and B. Lindner Eds. Rock!: Jugend und Musik in Deutschland. Bonn: Bundeszentrale für polit. Bildung: 62-69.

Statistisches Bundesamt. 2014. Staat \& Gesellschaft - Bevolkerung. https://www.destatis.de/EN/FactsFigures/Indicators/LongTermSeries/Population/l rbev04.html; Accessed: 3 January 2014.

Sterne, J. 2003. The Audible Past: Cultural Origins of Sound Reproduction. Durham, NC: Duke University Press.

Stubbs, D. -

2013. The Soundtrack of Our Youth: Conny Plank Remembered. The Quietus. http://thequietus.com/articles/11376-conny-plank; Accessed: 19 March 2016.

2014. Future Days: Krautrock and the Building of Modern Germany. London: Faber \& Faber.

Taylor, F. 2012. Exorcising Hitler: The Occupation and Denazification of Germany. London: Bloomsbury.

Taylor, T.D. 2011. Strange Sounds: Music, Technology and Culture. New York: Routledge.

Wagner, C. 2013. Der Klang der Revolte: die Magischen Jahre des Westdeutschen Musik-Underground. Mainz: Schott.

Waldthausen, B. 2013. Popol Vuh. August. http://www.furious.com/perfect/popolvuhinterview.html; Accessed: 20 August 2014.

Watts, M. 1972. Deutsch Rock. Melody Maker 25, 15 April.

Wishart, T. 1986. Sound Symbols and Landscapes. In S. Emmerson Ed. The Language of Electroacoustic Music. London: Macmillan: 41-60.

Wollmann, H. 2000. Local Government Modernization in Germany: Between Incrementalism and Reform Waves. Public Administration 78(4): 915-936.

\section{Discography}

Ash Ra Tempel -

1972a. Schwingungen. Ohr Records, Germany.

1972b. "Traummaschine". Kosmische Musik, Ohr Records, July, Germany.

Can. 1972. Ege Bamyasi, United Artists Records, November, Germany.

Harmonia -

1974a. "Sonnenschein". Musik von Harmonia, Brain, January, Germany.

1974b. "Veterano". Musik von Harmonia, Brain, January, Germany.

1975. "Deluxe (Immer Wieder)". Deluxe, Brain, August, Germany. 
Neu -

1973a. Neu! 2. Brain, Germany.

1973b. "Hallo Excentrico". Neu! 2, Brain, Germany.

1975. Neu! 75. Brain, Germany.

Popol Vuh. 1972. "In Den Gärten Pharaos". Kosmische Musik, Ohr Records, July, Germany.

Schulze, K. -

1972a. "Ebene". Kosmische Musik, Ohr Records, July, Germany.

1972b. Irrlicht. Ohr Records, August, Germany.

1972c. "Land". Kosmische Musik, Ohr Records, July, Germany.

Tangerine Dream -

1971. Alpha Centauri. Ohr Records, March, Germany. Liner notes.

1972a. "Geburt". Kosmische Musik, Ohr Records, July, Germany.

1972b. "Origin of Supernatural Probabilities". Zeit, Ohr Records, August,

Germany.

1972c. "Sunrise in the Third System". Kosmische Musik, Ohr Records, July,

Germany.

1974. Phaedra. Virgin Records, 20 February, United Kingdom. Liner notes.

1985. "Phaedra". Phaedra, Virgin Records, United Kingdom.

Various. 1972. Kosmische Musik, Ohr Records, July, Germany.

Videography

BBC. 2009. Krautrock - The Rebirth of Germany, 23 October. 